TI 2012-074/3

Tinbergen Institute Discussion Paper
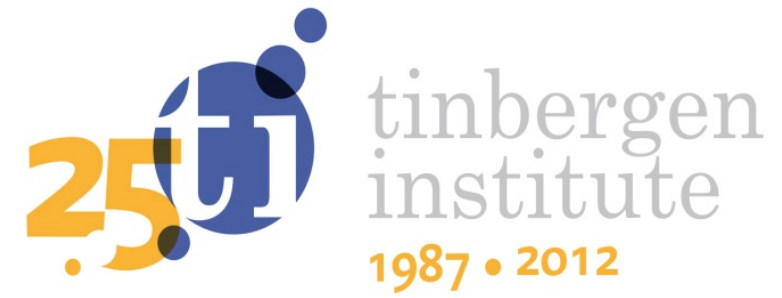

The $A B C$ of Housing Strategies:

Are Housing Assistance Programs

Effective in Enhancing Children's Well

Being?

José Rosero 
Tinbergen Institute is the graduate school and research institute in economics of Erasmus University Rotterdam, the University of Amsterdam and VU University Amsterdam.

More TI discussion papers can be downloaded at http://www.tinbergen.nl

Tinbergen Institute has two locations:

Tinbergen Institute Amsterdam

Gustav Mahlerplein 117

1082 MS Amsterdam

The Netherlands

Tel.: +31(0)205251600

Tinbergen Institute Rotterdam

Burg. Oudlaan 50

3062 PA Rotterdam

The Netherlands

Tel.: +31(0)10 4088900

Fax: $+31(0) 104089031$

Duisenberg school of finance is a collaboration of the Dutch financial sector and universities, with the ambition to support innovative research and offer top quality academic education in core areas of finance.

DSF research papers can be downloaded at: http://www.dsf.nl/

Duisenberg school of finance

Gustav Mahlerplein 117

1082 MS Amsterdam

The Netherlands

Tel.: +31(0)20 5258579 


\title{
The ABC of housing strategies: Are housing assistance programs effective in enhancing children's well-being?*
}

\author{
José Rosero
}

\begin{abstract}
This paper examines the effect of a housing assistance program on school enrollment, child labor and poverty reduction among poor families in Ecuador. Administrative data is merged to a household panel to link the history of a voucher application with socioeconomic information. Two empirical approaches are employed. First, I exploit variation in duration of the different stages to obtain a voucher and convert it into a house, using a sample of approved applicants. Second, I use variation across siblings that arises from the fact that siblings are exposed to the program at different ages. Results show that the program improves enrollment into post-compulsory education, decreases the probability that a child participates in the labor market and reduces the likelihood to live in poverty. Potential mediating factors are increased access to sanitation, better quality materials of the house and a reduced probability to live overcrowded.
\end{abstract}

JEL-codes: H53, I28, I38, R21

Keywords: Housing assistance programs; Housing voucher; Children; Fixed Effects; Within family estimators; Developing country; Ecuador

\section{Introduction}

The provision of houses and the improvement of housing quality is a common concern for societies in developed and developing countries. This conception is fueled by a widely held belief that housing is an important component of a basic package that is deemed to

*This version: June 2012. I would like to express my gratitude to Hessel Oosterbeek, Monique de Haan, Maarten Lindeboom, Erik Plug and seminar participants in Amsterdam, Buenos Aires, Quito and Santiago de Chile for their helpful comments. I would also like to acknowledge the support from the Ecuadorian government in providing the data. The usual disclaimer applies. The author is affiliated with the University of Amsterdam and the Tinbergen Institute. E-mail: j.a.roseromoncayo@uva.nl 
be necessary to have a good standard of living. From that perspective, adequate housing is considered to be a basic human right and an end in itself. Consistent with this idea, most governments in the world allocate substantial resources to housing assistance programs with the intention of providing adequate housing conditions to poor groups in the population. In developing countries, governments spend every year between $15 \%$ and $35 \%$ of their total investment in social policies on these type of programs (IADB, 2007).

Policies of housing assistance are usually considered as part of a safety net system which aim is to contribute to long term poverty reduction. This can be achieved through at least three channels. First, by subsidizing family income, housing assistance alleviates family's budget constraints that otherwise might crowd out other necessities of the house. Second, by providing a basis to create wealth (equity) and a mean to generate income through the involvement in productive activities. Third, it is argued that housing assistance programs have the potential to generate social externalities by building human capital of children in poor families (Green and White, 1997; Currie and Yelowitz, 2000; Newman and Harkness, 2002). Promoting children's human capital is considered to be a key element to reduce long term poverty as it improves their prospects to overcome intergenerational poverty traps.

Despite the alleged importance of housing as a factor influencing the well-being of children, the effects of housing assistance programs on children's outcomes have been seriously understudied (Almond and Currie, 2010). Moreover, most of the evidence that can be found in the literature applies to the context of developed countries where the vision on housing assistance differs greatly from that of developing countries. Housing assistance in developed countries consists mainly of financial assistance to poor families to afford the payment of renting one of the housing units that belongs to the public authorities (Public Housing Projects) or a unit in the private rental market through the provision of vouchers. In contrast, housing assistance programs in developing countries aim to provide financial assistance targeted to poor families to obtain an own and adequate house or to improve the quality of an existing owned dwelling (Buckley and Kalarickal, 2006; Arnott, 2008). The most popular program of this type in Latin America provides a single voucher that can be used to support part of the housing investment which is complemented by families' savings and a mortgage loan (Marcano, 2010). This is also known as a savings-vouchermortgage scheme or "ABC" for the Spanish words: Ahorro (savings), Bono (voucher), and Crédito (mortgage loan).

This paper aims to fill the gap in the development literature by investigating the effect of housing assistance programs on children's human capital and on poverty alleviation in developing countries. Specifically, I examine the impact of a greatly promoted ABC housing assistance program in Ecuador on school enrollment, child labor and its capacity 
to take a family out of poverty. An additional contribution of this paper is to go beyond the estimation of the impact of the program, by examining the potential mechanisms through which effects might work.

In order to estimate an effect I combine administrative data from the $\mathrm{ABC}$ program to a household panel data (SELBEN panel data) that is used to target social benefits in Ecuador. This allows me to link the history of a voucher, from its moment of application to the moment when a family succeeds in converting the voucher into a house, to socioeconomic information of the household and their children both before and after the intervention. The empirical analysis applies two strategies to identify a causal effect of the program. First, I exploit variation in duration of the different stages involved in obtaining the voucher and converting it into a new house to construct comparable treatment and control groups. I do this using a sample of approved applicants to the program and controlling for different sources of endogenous variation. Second, I use the variation across siblings within families that arises from the fact that siblings are exposed to the program at different ages. The comparison of the results of these different strategies is used to provide an indication of the causal effect of the program on children's outcomes.

I find that the program significantly increases the probability of school enrollment for children aged 15 to 18 . This is especially relevant for public policy as it represents the transition age from compulsory to post-compulsory school where many students drop out from the educational system. In parallel with the increase of school enrollment, the program decreases the probability of a child to participate in the labor market in the same age interval which may be interpreted as an indication of the substitutability between education and labor at this age. Furthermore, I find that this type of housing assistance has a positive impact on increasing the level of welfare of a family, therefore, reducing its likelihood to be considered poor. These estimates are tested for alternative interpretations that might interfere with the pattern of results. Finally, it is shown that a possible mediating mechanism that can partially explain the observed effects on school enrollment is through the improvement of the physical environment of the house measured by the increased access to sanitation, better quality materials of the dwelling and a reduced probability to live in an overcrowded condition. At the same time, there is no evidence of the presence of neighborhood effects driven by the reallocation of families into better neighborhoods.

The remainder of the paper is organized as follows. The next section provides a brief overview of the theoretical links between housing assistance programs and children's outcomes, and presents the main findings available in the economic literature. Section 3 describes the context of housing investment in Ecuador and provides further details of the housing assistance program. Section 4 outlines the data used for the analysis. Section 5 describes the two empirical approaches used to identify the effects of the program and 
their assumptions. Section 6 presents the results, tests for alternative interpretations and elaborates on the potential mechanisms that may explain the effects. Section 7 summarizes and concludes.

\section{Existing literature}

\subsection{Theoretical links}

Housing assistance is expected to have an effect on child outcomes through different mechanisms. First, housing assistance may provide a better physical environment to families than the one experienced in the absence of the program. A better environment includes greater access to clean water, basic sanitation or garbage disposal, improved materials of floors and roofs and a smaller likelihood of a house to be overcrowded. All of these might be considered as inputs in a health production function which is itself related to educational achievement (Becker, 1964; Grossman, 1999). There are a number of studies that document the association between overcrowding and children's poor health (Mann et al., 1992; Coggon et al., 1993), and also the negative effects of living in an overcrowded home on children's performance at school (Goux and Maurin, 2005). In a recent paper, Cattaneo et al. (2009) also suggest that there is a positive effect of upgrading dirt floors to cement floors in improving the health status and the cognitive development of children.

Second, the relocation of families into new locations induced by housing assistance programs may provide families with the opportunity to move to better neighborhoods. Neighborhood quality may have positive effects on children's educational outcomes by increasing the exposure of children to more advantaged peers or better role models (Jencks and Mayer, 1990; Brooks-Gunn et al., 1997). In addition, it may also have positive effects by increasing access to better social networks or local public goods such as schools and libraries (Ellen and Turner, 1997; Hoxby, 2000).

A third mechanism through which housing assistance may affect children's educational outcomes is residential stability. Given the transaction costs of moving, families that become homeowners are also more likely to be stable in the long run (Aaronson, 2000). If the stability created by homeownership leads to more social capital in the form of more attachment to the school system, teachers and peers, it can be considered a mechanism that may mediate this relationship. There is substantial evidence in the literature that documents the negative association of frequent school mobility on student achievement (Astone and McLanahan, 1994; Kerbow, 1996; Hanushek et al., 2004).

Fourth, housing assistance may have an impact on the behavior or attitudes of parents towards their children. Several studies have documented the effects of improved housing on the level of self-esteem, happiness, anxiety, depression and other kinds of psychologi- 
cal distress. Rossi and Weber (1996) found that better housing increases household's life satisfaction and happiness. Elton and Packer (1996) showed that improved housing quality reduces anxiety and depression among adults. Given these pathways, parents are more likely to create an adequate home environment for their children which is considered to be a key determinant of the educational attainment of a child (Rosero and Oosterbeek, $2011 ; ?)$.

Fifth, housing assistance may affect children's outcomes through at least two types of income effects. First, by lifting budget and liquidity constraints which might increase the amount of resources that a family can invest on children's education. Several experimental and non-experimental studies in developing countries have documented the causal effects of income transfers in increasing school enrollment and decreasing the probability of child labor (Schultz, 2004; Edmonds, 2005; Oosterbeek et al., 2008). The second type of income effect comes from the realization that a house might be used to generate income or overcome credit constraints. De Soto (2000) argues that having a house where the property rights are well defined might give the right incentives to individuals to either invest in productive assets for a home business or to use the house as collateral for credits. As a result, the generated income may be used to purchase items or make additional investments related to a child's education.

\subsection{Previous findings}

The empirical evidence about the effects of housing assistance programs on children outcomes is thin for developed and developing countries (Almond and Currie, 2010). In developed countries this kind of analysis has been motivated by the public discontent about housing projects as a policy of housing assistance, and the shift to vouchers to be used by poor families as a mean of payment to rent a house. In contrast, studies in developing countries are motivated by the need of governments to evaluate voucher programs that promote the access of poor families to a new and adequate house, or that improve the physical condition of an existing house.

Currie and Yelowitz (2000) explore the effects of living in public housing projects in the United States on house quality and educational attainment. To address the endogeneity of program receipt, they follow a two sample instrumental variable approach where the probability of living in a project is instrumented by the sex composition of siblings in families with two children. They find that treated families are less likely to live in an overcrowded environment and that children in the program are also less likely to be held back in school.

Jacob (2004) compares the effects of living in a public housing building to a program of vouchers that promotes families to move to private housing in the Chicago metropolitan 
area. For identification, Jacob makes use of a series of high rise building demolitions as an instrument to compare children in families that were transferred to another building and families that were offered the voucher. The results suggest that, compared to vouchers, public housing participation has no additional impact on student achievement.

Using an experimental design, Sanbonmatsu et al. (2006) explore the benefits of a voucher-based assistance program on educational outcomes in five major cities of the United States. The analysis makes use of the Moving to Opportunity program (MTO) that randomly assigned families that voluntarily wanted to be reallocated away from public housing to three different groups: (i) a treatment group in which families received a voucher to be used to rent a house in low poverty areas and also received external assistance to find a new place, (ii) a treatment group that received a voucher without any requirements of location and assistance, and (iii) a control group that did not receive a voucher or any assistance. Compared to the control group, they find no significant effect on test scores or behavior of the children in either of the treatment groups despite the fact that children lived on average in better neighborhoods.

Fertig and Reingold (2007) examine the effect of moving into public housing on children's health outcomes. Using data from the Fragile Families Study in the United States, they compare families living in public housing buildings with families that are eligible for the program. To control for endogeneity of public housing participation the analysis uses three instruments: gender composition of siblings, variation of public housing supply in each location, and the variation across cities in the length of waiting lists to get a house. The results show that there is no significant effect of public housing on child health status or the likelihood of a child to be malnourished.

In an attempt to evaluate $\mathrm{ABC}$ voucher programs in Latin America, the Interamerican Development Bank promoted a series of impact evaluation studies analyzing the cases of Chile, Colombia, Panama, Costa Rica and Ecuador (Marcano and Ruprah, 2008; Pecha, 2011; Pecha, 2010; Nadin and Almanza, 2010; Marcano, 2010). All these studies used cross-section data coming from household surveys and applied a propensity score matching methodology to try to control for the selection bias of program participation. The results presented by these studies vary. While there are significantly positive effects of receiving the voucher on school attendance for children between 6 and 14 years old in Colombia and for girls between 10 and 14 years old in Costa Rica, there is no effect of the program for the cases of Chile, Ecuador and Panama. However, these studies suffer from three important limitations. First, they use rather small samples as the household surveys identify a small number of beneficiaries of the program. ${ }^{1}$ Second, the treated ob-

\footnotetext{
${ }^{1}$ Using the Living Conditions Measurement Survey of 2006, Marcano (2010) identifies only 43 households that were exposed to the program in Ecuador.
} 
servations correspond to families that have received the voucher but it is not known if the families where able to convert it into a new house. Third, the identification strategy used in these studies does not take into account the possible endogeneity due to unobservable variables that affect the choice to apply to the program and might be also correlated with child outcomes. The analysis presented in this paper overcomes these limitations as it uses administrative data with a large sample of applicants, that can identify families in different stages of the program and exploits a more credible strategy to identify an effect.

\section{Context and intervention}

\subsection{Context}

Ecuador is a lower middle income country with a population of 13 million inhabitants living in 3.3 million housing units. The country is characterized by a large share of its population living in poverty and by an unequal income distribution. In 2006, around 38\% of the Ecuadorian population were considered poor as their per capita consumption was below the national poverty line.

Compulsory education in Ecuador starts at the age of 6 years and ends at the age of 14. Post-compulsory schooling, comprises three additional years starting at the age of 15 and is considered to be a prerequisite for higher education. Enrollment in basic schooling is almost universal (around 94\%), but drops sharply at the transition age from compulsory to post-compulsory education (less than $70 \%$ ). In line with educational statistics, child labor rises sharply in this transition age from $4 \%$ at the age of 14 years old to $10 \%$ at the age of 15 (Ecuadorian Labor Survey 2009). ${ }^{2}$ As expected, the drop in enrollment and the rise in child labor is more pronounced for children from poor families.

As in most countries in Latin America, in Ecuador housing is considered to be a key element of a basic package necessary for a good standard of living. Despite this fact, four out of ten households do not own a house and $27 \%$ of the homeowners declare not to have legal tenure of the house. Ecuador's quantitative housing deficit in 2009 was estimated at about 717 thousand units needed to give accommodation to homeless people and also to replace units which are considered to be insufficient (located in areas not suitable for residential purpose or built using non durable materials). Around $64 \%$ of this deficit is concentrated in families that belong to the poorest 40 percent of the country and every year the demand for housing increases by 54 thousand units (MIDUVI, 2010). In addition to the quantitative gap, there is qualitative shortage of adequate housing reflected in $52 \%$ of the households that lack access to safe drinking water, $50 \%$ that have no access to

\footnotetext{
${ }^{2}$ These figures exclude children that both work and go to school.
} 
adequate sanitation and $26 \%$ of the households that are considered to be overcrowded. ${ }^{3}$

A small formal unsubsidized mortgage market exists in Ecuador to finance investments in housing. While this market serves the demand of middle and high income families, low income families typically lack the collateral needed to have access to credit. This borrowing constraint prevents low income families from buying commercially built houses. ${ }^{4}$ The latter combined with a rental market that is segmented and functions poorly ${ }^{5}$, results in most of the housing investment of low income families to occur progressively over a long period of time (Frank, 2004; Ferguson and Navarrete, 2003). Typically a household acquires land through different means specially by squatting private or public property or by the division of parents' land. After building a temporary dwelling to secure the land, families start a gradual process in which families improve the structure of the house, work in the legal tenure of the house and even lobby for basic services. The result of the progressive housing process is that poor families, for an important part of their lives, live in unsanitary and disrupted environments that lack from basic amenities (Ferguson and Navarrete, 2003).

The government's approach to housing subsidies has been traditionally supply-sided through public institutions that used to concentrate all the processes of providing a new house for low income people. The processes included land acquisition, house construction, the development of a loan and saving system and the qualification of families for loans at subsidized mortgage rates. From 1998 onwards, the Ecuadorian government implemented a shift in its policy adopting a demand-side approach based on vouchers. ${ }^{6}$ The system was conceived as a mechanism to enable families to rely on markets to increase their ability to consume housing of a particular type at the lowest cost to the government (Buckley and Kalarickal, 2006).

\subsection{Description of the program}

To shift to a demand based approach, the Ecuadorian government created a new nationwide program in 1998 called Housing Incentive System. ${ }^{7}$ The main objective of the program is to improve the living conditions of poor families by giving them financial support to either buy a new and adequate house or to improve the quality of their current house. With this program, the government aims to reduce the country's housing shortage.

The program benefit consists of a subsidy given to families through a voucher that

\footnotetext{
${ }^{3} \mathrm{~A}$ household is considered to be overcrowded if three or more people sleep in the same single bedroom.

${ }^{4} \mathrm{~A}$ typical house that can be acquired on this market in 2009 is estimated to have a market value of US $\$ 40,000$. In contrast, a house for a low income family is valued in a range of US\$8,000 to US\$12,000.

${ }^{5}$ While $9.3 \%$ of families in the poorest quintile rent a house, $21 \%$ in the richest quintile do so.

${ }^{6}$ A similar approach was adopted in most of Latin American countries among them Chile, Colombia, Costa Rica, Dominican Republic, Nicaragua and Panama.

${ }^{7}$ In Spanish, the program is called "Sistema de Incentivos de Vivienda" or simply "Bono de Vivienda".
} 
is complemented by the beneficiary's own savings and a mortgage loan. The design is known as an $\mathrm{ABC}$ scheme for the Spanish words for savings-voucher-mortgage. The program has two components: one promotes new housing and the other supports housing improvement. This paper focuses on the effects of the first component mainly due to the absence of trustworthy administrative data on the second component. Moreover, around $85 \%$ of the vouchers issued by the program are given for the purchase of new houses.

Within the new housing component, applicants to the program can apply to buy a house with a maximum value of US\$20,000. Applicants need to prove that at least $10 \%$ of the total value of the house is held in a savings account. The amount of the voucher is US\$5,000 which is 10 times the value of a monthly basic consumption bundle in Ecuador. The difference between the estimated cost of the house and the amount of the voucher plus savings can be borrowed as a mortgage loan provided by any financial institution registered with the program at the market interest rate. The program is managed and operated by the Ministry of Housing.

To be eligible for the program, none of the members of the applicant family should own a dwelling in the country. ${ }^{8}$ Additionally, the family's monthly income should not exceed US\$654 and the family should be ranked among the $60 \%$ poorest households in the database of SELBEN which is used in Ecuador to target social benefits. ${ }^{9}$

Between 1999 and 2006, around 53,000 vouchers for a new house were issued. From 2007 to 2009 the program became more active and around 103,000 vouchers for new housing were awarded and paid out. During this last period the program invested US\$521 million which represents $0.8 \%$ of Ecuador's GDP and $20 \%$ of the total investment of the government in the social sector.

\subsection{Procedure}

The procedure to obtain a voucher and a new house entails some steps and involves several actors. Figure 1 summarizes the procedure. In the first step the applicant presents some documents at the regional offices of the Ministry of Housing. These documents include certificates stating the applicant's income and savings and a proof that none of the family members owns a house issued by the land-registration office. Families can apply at any time of the year.

At the second step, local personnel of the Ministry of Housing evaluates the docu-

\footnotetext{
${ }^{8}$ According to the program, a family is composed of: head, spouse and children under 18 years old.

${ }^{9}$ SELBEN, is a census type database that has information about household and family's socio-economic characteristics of 2.5 million households (78\% of the Ecuadorian households) from geographical zones previously targeted by a poverty map. With this information, an index of socioeconomic status is computed and, according to this index, the households are ranked by their relative position. This dataset is also used to target programs such as the government's cash transfer program and several nutritional programs.
} 
Figure 1. Procedure of the $\mathrm{ABC}$ housing assistance program

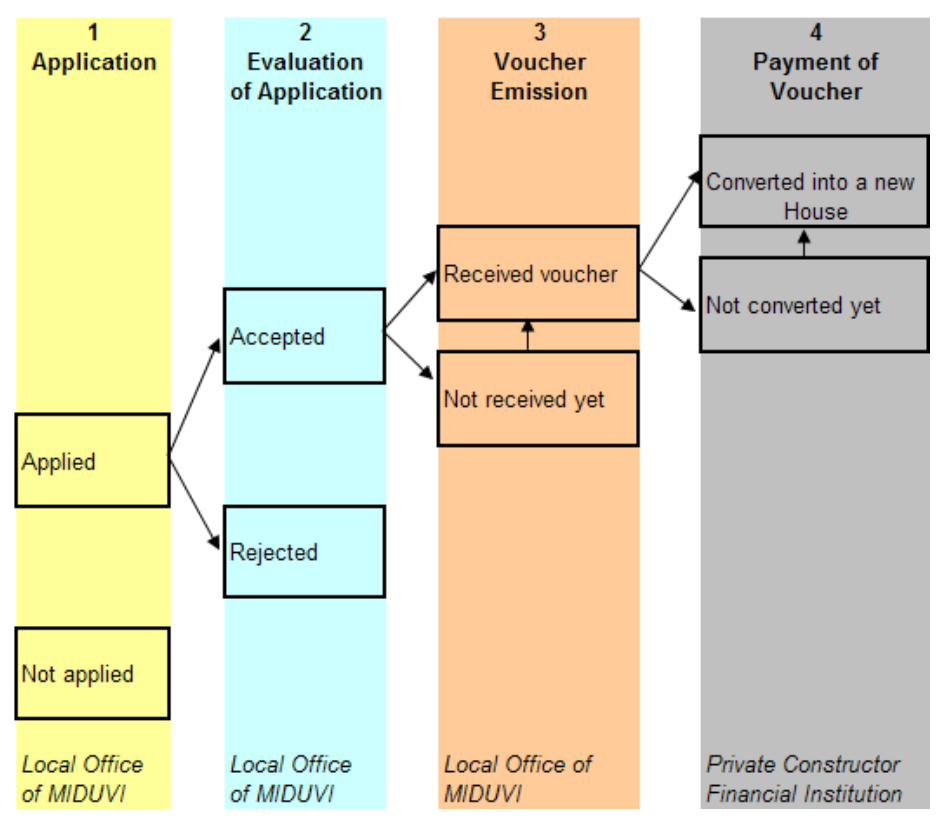

ments submitted by the applicants. This entails the validation of the documents and the comparison of the application with the information in the SELBEN database. Applications are evaluated in order of submission; first come, first served. An application is either accepted or rejected.

The third step is the voucher's emission which is made at the local offices of the program in each province. All accepted applications are awarded as long as the annual budget of the program has not run out. A single-page document signed by the local authority of the Ministry of Housing is handed over to each accepted family, therefore, the subsidy is not paid in cash to the family. A family can not receive more than one voucher during its lifetime.

The last step is the actual payment of the voucher which requires that the family found a suitable dwelling and, in most cases, applied and received a mortgage loan. To find a house, beneficiaries get in contact with one of the private construction projects that have been registered in the program's offices and that offer houses with a value of at most US $\$ 20,000$. Once agreed on the purchase, families transfer the voucher to the private constructor as mean of payment. In parallel, beneficiaries may apply for a mortgage, using the house as a collateral, with one of the financial institutions that are registered in the program.

At the moment that the voucher is claimed by the constructor an expense is accounted by the program and a new house is effectively granted to the beneficiary. Therefore, in the analysis, the payment of the voucher is considered to be the true indicator that a family possesses a house. Although the program administrators have no means to monitor the 
quality of the house delivered by the constructor, a typical house should be around 50 square meters, with at least two bedrooms, built with adequate and resistant materials, and must have proper connection to the public networks of water and sanitation. The average time between application and receipt of a house is 8 to 9 months. The average time between obtaining the voucher and converting it into a new house is 6 to 7 months.

\section{Data and main outcome variables}

\subsection{Data}

To estimate the effect of the housing program on school enrollment and child labor, I combine two datasets. The first dataset comes from the administrative records of the program provided by the Ministry of Housing. The dataset contains the approved applications for the new house component of the program during the period from April 2007 to October 2009 in urban areas. A family is identified in this dataset by the national identification number (ID number) of the applicant. The database contains complete information on the progress of the application until the moment when the voucher is paid out. The information includes the date of the voucher's approval, the date on which the voucher is issued and the date at which the voucher is paid out and converted into a house. The database does, however, not include the date of application. The administrative dataset contains 26,288 approved applications for a new house.

The second source of information is the panel data of the first and second round of SELBEN. The panel data has census-type socioeconomic information of 1.5 million households and includes data on infrastructure of the dwelling, household composition and personal characteristics of the household members such as gender, age, civil and labor status and educational achievement. The first wave was taken between 2001 and 2006, the second wave was collected in 2008 and 2009. Eighty percent of the observations in the first wave were surveyed in the period 2001-2003 and 93\% of the households in the second wave were surveyed in 2008.

I merge the administrative records from the Ministry of Housing with the SELBEN panel using the national identification number. In this way I am able to link the history of a family's voucher application with socioeconomic information of the household, household composition and characteristics of the children of these families before and after the intervention. While the identification strategy will be explained in the next section, the combination of datasets gives me an opportunity to determine whether a child, at the moment of the second SELBEN survey, was living in a family that applied to the program, was approved and was able to convert it into a house (treated children) or whether a child was living in a family that applied to the program, was approved and had not been able 
yet to convert it (control children).

One limitation of the SELBEN data is that, at the moment of the survey, the enumerators were instructed to obtain at least one ID of an adult per household, mainly the ID of the spouse who is likely to be around the house more often than the household head. Given this limitation, the merging exercise was successful for 7,749 households from the administrative records to the SELBEN panel by the ID of some of its adult members. The sample used in the analysis is a subsample of this dataset. First, the sample was restricted to households that had at least one child between 6 years old and 18 years old in the first SELBEN survey. This reduces the sample to 4,106 households with 6,537 children. Second, to capture the effects of the program, the definition of the treated children was restricted to households that converted the voucher at least 180 days before the second survey of SELBEN which is considered by the program administrators the minimum amount of time to expect any short run effect of the program. ${ }^{10}$ This reduces the sample to 4,737 children in 2,986 households. Finally, as I analyze the impact of the program on school enrollment and child labor, I consider children not older than 18 years at the moment of the second SELBEN survey. The sample of analysis consists of 3,304 children in 2,342 households. The children in this sample were born between 1986 and 2002. The mean exposure of the treated group in our sample is 328 days.

The main characteristics of the sample of analysis in the second SELBEN survey are presented in the first column of Table 1 while the characteristics for all families that might be considered as potentially eligible for the program in this survey is presented in the second column. ${ }^{11}$ Children in the sample of analysis are equally distributed between boys and girls with an average age of 14 years old, an enrollment rate (age 8 to 18 years old) of $86 \%$ and a child labor participation of $11 \%$. These children live in families that on average have 5 members, the average age of their mothers is 41 years old and the level of schooling of their parents is around 7 years of formal education. Compared with the characteristics of this sample, the children that belong to the group of potential eligible families for the program are on average two years younger, live in slightly poorer families given the socioeconomic SELBEN index, have less educated parents and less access to basic services of sanitation and water. Despite these differences, the children in the two samples have on average the same enrollment rate and the same level of labor participation.

\footnotetext{
${ }^{10}$ Table 7 presents results based on a definition of treated children in which the time between converting the voucher and the second SELBEN survey (exposure time) was less than 180 days. As the program administrators predicted, the results show that having an exposure of less than 180 days does not have an impact on any of the children's outcomes considered.

${ }^{11}$ Eligible families in the second SELBEN survey is defined following the parameters of eligibility of the program. This is, families that are in the poorest three quintiles of the SELBEN socioeconomic index, and that report not owning a house.
} 
Table 1. Descriptive statistics

\begin{tabular}{|c|c|c|}
\hline Variable & $\begin{array}{l}\text { Sample of analysis } \\
\text { (1) }\end{array}$ & $\begin{array}{c}\text { Eligible universe }^{a} \\
\text { (2) }\end{array}$ \\
\hline Enrollment (age 8 to 18 ) & $\begin{array}{c}0.858 \\
(0.349)\end{array}$ & $\begin{array}{c}0.871 \\
(0.336)\end{array}$ \\
\hline Child labor (age 8 to 18 ) & $\begin{array}{c}0.108 \\
(0.311)\end{array}$ & $\begin{array}{c}0.093 \\
(0.291)\end{array}$ \\
\hline Gender & $\begin{array}{c}0.516 \\
(0.500)\end{array}$ & $\begin{array}{c}0.516 \\
(0.500)\end{array}$ \\
\hline Age (years) & $\begin{array}{l}14.604 \\
(2.143)\end{array}$ & $\begin{array}{l}12.202 \\
(2.832)\end{array}$ \\
\hline$N$ children & 3,304 & $1,924,622$ \\
\hline Access sanitation & $\begin{array}{c}0.759 \\
(0.428)\end{array}$ & $\begin{array}{c}0.619 \\
(0.486)\end{array}$ \\
\hline Access floor & $\begin{array}{c}0.914 \\
(0.281)\end{array}$ & $\begin{array}{c}0.859 \\
(0.348)\end{array}$ \\
\hline Access shower & $\begin{array}{c}0.541 \\
(0.498)\end{array}$ & $\begin{array}{c}0.427 \\
(0.495)\end{array}$ \\
\hline Overcrowding & $\begin{array}{c}0.393 \\
(0.489)\end{array}$ & $\begin{array}{c}0.323 \\
(0.467)\end{array}$ \\
\hline Selben index & $\begin{array}{l}44.544 \\
(6.847)\end{array}$ & $\begin{array}{l}38.224 \\
(7.448)\end{array}$ \\
\hline Household size & $\begin{array}{c}5.019 \\
(1.859)\end{array}$ & $\begin{array}{l}4.162 \\
(2.100)\end{array}$ \\
\hline Number of adults in $\mathrm{HH}$ & $\begin{array}{c}2.463 \\
(1.232)\end{array}$ & $\begin{array}{l}2.275 \\
(1.165)\end{array}$ \\
\hline Number of children in $\mathrm{HH}$ & $\begin{array}{l}2.556 \\
(1.346)\end{array}$ & $\begin{array}{c}1.887 \\
(1.594)\end{array}$ \\
\hline Schooling mother (years) & $\begin{array}{c}7.192 \\
(3.872)\end{array}$ & $\begin{array}{c}6.751 \\
(3.903)\end{array}$ \\
\hline Schooling head (years) & $\begin{array}{c}6.957 \\
(3.816)\end{array}$ & $\begin{array}{c}6.675 \\
(3.815)\end{array}$ \\
\hline Age mother (years) & $\begin{array}{l}41.902 \\
(9.484)\end{array}$ & $\begin{array}{c}41.720 \\
(16.237)\end{array}$ \\
\hline If $\mathrm{HH}$ head is indigenous & $\begin{array}{c}0.006 \\
(0.074)\end{array}$ & $\begin{array}{c}0.049 \\
(0.215)\end{array}$ \\
\hline If $\mathrm{HH}$ head is employed & $\begin{array}{c}0.878 \\
(0.327)\end{array}$ & $\begin{array}{c}0.828 \\
(0.377)\end{array}$ \\
\hline If $\mathrm{HH}$ head earns income & $\begin{array}{c}0.956 \\
(0.205)\end{array}$ & $\begin{array}{c}0.833 \\
(0.373)\end{array}$ \\
\hline If $\mathrm{HH}$ head is disabled & $\begin{array}{c}0.022 \\
(0.146)\end{array}$ & $\begin{array}{c}0.048 \\
(0.213)\end{array}$ \\
\hline Nhouseholds & 2,342 & $1,623,178$ \\
\hline
\end{tabular}

Note: Descriptive statistics of the sample of analysis at the moment of the second SELBEN survey. Mean values and standard deviations in parentheses.

${ }^{a}$ The descriptive statistics for variables at the level of the children are based on a sample of children between 8 and 18 years old. 


\subsection{Outcome variables}

The main outcomes in the analysis are school enrollment and child labor. The analysis uses two definitions of school enrollment. The first one is enrollment of child $i$ at the moment of the first or second SELBEN survey which is based on the following question from the questionnaire: "Are you enrolled in the present schooling year?". The second definition is enrollment of child $i$ at age $a$ which combines the question described above, and the following question: "Which is the highest level and grade of education that you have achieved?". The latter allows me to infer whether or not the child was enrolled at a certain age. For example, if a child is older than 16 in the second SELBEN survey and is currently enrolled, the child is assumed to also have been enrolled at age 16. In the same way, if a child older than 16 in the second SELBEN survey is not currently enrolled but the highest level achieved by the child is higher or equal to the level that he should have had at age 16, then it is inferred that the child was enrolled at age 16.

Child labor is defined as participation in the labor market. It includes not only having a job but also searching actively for a job in the week prior to the interview. ${ }^{12}$ In both SELBEN surveys, this question is answered by all individuals older than five years old.

As an additional outcome, I am interested to analyze the effect of the program on improving the well-being of families and reducing poverty. While the SELBEN survey does not include questions that measure the income or consumption of a person or the household, the questionnaire includes questions that can be combined to construct a poverty index using a composite welfare approach. The analysis presented below consider two definitions of welfare. The first definition corresponds to the SELBEN index which is used by the Ecuadorian authorities to target social programs to poor families. The SELBEN index includes information on individual characteristics (demographic composition, education levels, employment of household members), wealth measured by the possession of assets and durable goods, dwelling characteristics (floor quality, number of rooms) and access to services (sanitation, safe water, electricity). This information is aggregated by non linear principal components into a welfare index that summarizes the socioeconomic condition of a family and ranks it relative to other families in the sample. A lower index represents a poorer family. ${ }^{13}$ As this index contains variables that are mechanically

\footnotetext{
${ }^{12}$ From the group of children participating in the labor market, $15 \%$ were searching for a job in the week prior to the interview. The results for child labor presented in the next section are not sensitive to the exclusion of this group of children.

${ }^{13}$ The variables included in the SELBEN index are: whether a family leaves in the urban sector, quality of the floor, access to electricity inside the house, access to shower, access to sanitation, type of energy used to cook, number of rooms, number of children under 6 years old, number of income earners, ethnicity of the family head, educational level of head and spouse, access to credit and land, access to health insurance, number of children between 5 and 15 years old not enrolled in school, type of school in which the children are enrolled, number of family members with a disability, whether has a television, a DVD device, a car, a refrigerator, a stove, a stereo and a telephone line. The same weights computed by the principal component
} 
affected by the intervention, the second definition of welfare leaves out from the aggregation the information of dwelling characteristics and access to services. The comparison of the results of both indexes will allow us to test if the effect of having a new house on the poverty measurements is sensitive to the exclusion of the infrastructure related variables.

\section{Empirical approach}

If the housing program would have been randomly assigned, one could estimate the effect of receiving the voucher program by comparing children living in families which applied to the program with children in families that did not apply for the program. As described in Section 3, both placement into the program and the decision to apply are far from random as placement is targeted to poor families and the decision to apply reflects a choice made by eligible families. As a result, the direct comparison between applicants and non applicants would result in a biased estimate of the effect of the program.

Moreover, we are interested in estimating the effect of having a new and adequate house which is the final intention of the program. The estimation of this effect is subject to an additional source of endogeneity as it entails the ability of a family to convert the voucher which may depend on unobservable characteristics that are likely to affect the outcomes. Failure to control for these variables would also result in a biased estimate of the effect of the program.

To control for selection bias and identify a causal effect of the program, I employ two different empirical approaches. It is by comparing the results between these approaches that I may give an indication of the impact of the program on children outcomes.

The first approach for identification exploits the variation in time of the different stages involved to obtain a voucher and convert it into a house and the variation in timing of the second SELBEN survey to construct comparable treatment and control groups. Figure 2 depicts the distribution of the date of payment of the voucher (realization of a house) and the date of the second SELBEN survey and points out the fact that the period of the survey coincides with the normal implementation of the program. While $93 \%$ of the cases where surveyed in 2008, $60 \%$ of them applied and converted the voucher before December 2008. Thus, conditional on application and approval of the application, I can compare children in families that were able to convert the voucher and have a house before they were surveyed by the second wave of SELBEN (treated group), to children in families that applied, were approved, but converted the bonus in a period after the SELBEN survey (control group). By comparing within the group of approved applicants I manage to control for the endogeneity that arises from the eligibility criteria of the

analysis are used to create both the pre and the post intervention index. 
Figure 2. Density of time variables

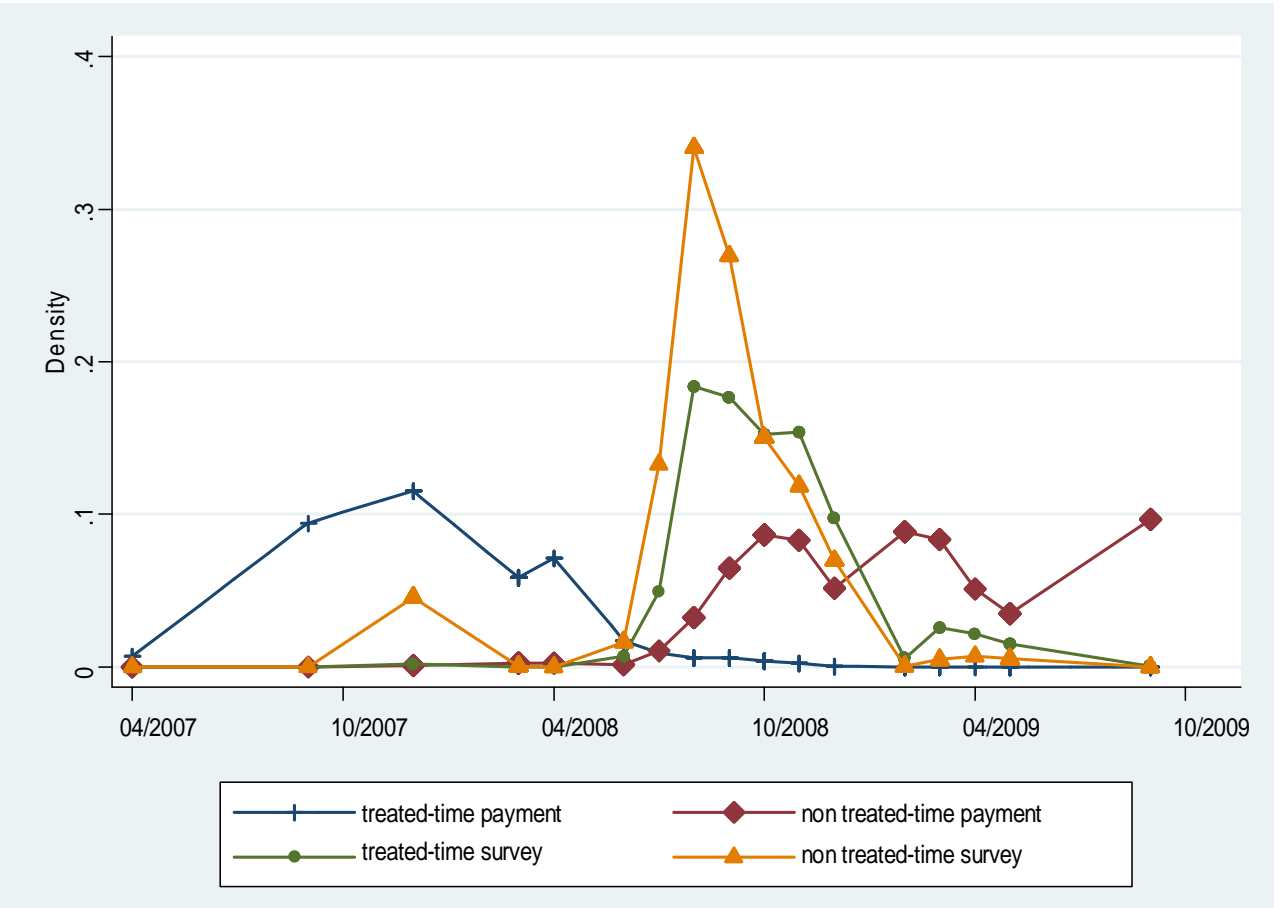

program, and the choice of the families to apply for a voucher.

Table 2 presents $p$-values from a test of differences in pre-intervention characteristics between the treated and control groups. Although comparing groups within the subsample of approved applicants is intuitively better than using a sample of non-applicants or rejected applicants as control groups, the table reports that while most of the characteristics are balanced between groups there are some small but statistically significant differences. A child in the treated group is on average 0.2 years older, has a household head that has 0.3 more years of education and a household spouse that has 0.5 more years of education than a child in the control group. In terms of pre-intervention outcome variables the only significant difference is in access to sanitation where a treated child has a 5 percentage point higher likelihood of living in a house with adequate access than its non-treated counterpart. In the analysis below I control for these observed differences.

The causal interpretation of any result that compares the treated and untreated groups depends on the exogeneity of three time variables which are the sources of variation used for identification: (i) the time of the application, (ii) the time of the second survey of SEL$\mathrm{BEN}$, and (iii) the time that elapsed from getting the voucher to converting the voucher. These variables are likely to be non-random as they may be correlated with unobservables that influence the outcomes. Examples include the urgency with which a family needs a house, the availability of information of the program that is accessible to the families in the different stages of the process, and the ability and skills of the family to go through a 
Table 2. Differences pre-intervention by treatment status

\begin{tabular}{lccc}
\hline Variable & $\begin{array}{c}\text { Controls } \\
(1)\end{array}$ & $\begin{array}{c}\text { Treated } \\
(2)\end{array}$ & $\begin{array}{c}\text { p-value } \\
(3)\end{array}$ \\
\hline \multirow{4}{*}{ Outcomes } & & \\
Enrollment & 0.966 & 0.962 & {$[0.603]$} \\
Child labor & 0.003 & 0.006 & {$[0.235]$} \\
Access sanitation & 0.363 & 0.41 & {$[0.072]$} \\
Access floor & 0.846 & 0.852 & {$[0.760]$} \\
Access shower & 0.137 & 0.144 & {$[0.721]$} \\
Overcrowding & 0.571 & 0.552 & {$[0.463]$} \\
& Controls & & \\
Gender & 0.517 & 0.514 & {$[0.889]$} \\
Age & 8.747 & 8.905 & {$[0.022]$} \\
Selben index & 43.943 & 44.432 & {$[0.185]$} \\
Household size & 5.05 & 5.076 & {$[0.782]$} \\
Number of adults & 1.986 & 2.027 & {$[0.277]$} \\
Number of children & 3.064 & 3.049 & {$[0.827]$} \\
Schooling mother & 6.919 & 7.461 & {$[0.010]$} \\
Schooling head & 6.782 & 7.116 & {$[0.068]$} \\
Age mother & 41.704 & 41.593 & {$[0.789]$} \\
If HH head is indigenous & 0.011 & 0.021 & {$[0.187]$} \\
If HH head is employed & 0.901 & 0.898 & {$[0.827]$} \\
If HH head earns income & 0.977 & 0.972 & {$[0.545]$} \\
If HH head is disabled & 0.009 & 0.013 & {$[0.469]$} \\
$N$ & 2192 & 1112 & \\
\hline Note: Mean values and standard errors in parentheses. $p$ values, in brackets, are based on t-test for equality \\
of means. & & & \\
& & &
\end{tabular}


process that involves several actors and links with different markets. If the least capable families were least likely to convert the voucher into a house, for example, we might expect untreated children to have worse outcomes than treated children, also in the absence of the intervention. This would bias the estimated effects upwards.

To get some indication about the exogeneity of the time variables, Table 3 regresses the time to convert the voucher and the time of the SELBEN survey on different preintervention variables taken from the first wave of SELBEN. Each estimate results from a separate regression of the time variable on a specific household characteristic. As the table shows, while the time needed to convert the voucher is positively related to household size and number of children (both proxies of the need of a family to get a new house), the date of the survey is positively related to the ethnic origin of the household head and also with household size. ${ }^{14}$ The table also points out that families in the treatment group take on average 27 days less to convert the voucher than non-treated families, and are surveyed on average 42 days later than non-treated families.

In order to control for the potential bias due to the endogeneity of the time variables, I include the available information on these variables in the empirical strategy to compare (i) children of families that were surveyed by SELBEN in the same period of time $T_{j}$, and (ii) children of families that spend the same amount of time to convert the voucher $D_{j}$. The approach is presented graphically in Figure 3 where $H_{j}$ is an indicator variable for the intervention that switches on for treated families. The identifying assumption, in this case, is that after controlling for the time that a family takes to convert the voucher, and the date of the survey, the date of application is random. I consider this to be a plausible assumption as time of application and time for conversion are likely to depend on the same type of unobservables such as need, lack of information and the ability of the family to go through the process. At this point it is also important to remember that families can influence neither the process of evaluation of applications nor the time of emission of the voucher whose duration is exogenous. The strategy is complemented by comparing children that are of the same age when surveyed by SELBEN in order to address the fact that the children were not surveyed at the same time and that older children have a higher probability to drop out of school and enter the labor market than younger children.

Formally, the first approach gives us the following empirical equation:

$$
Y_{i j}=\alpha_{1}+\beta_{1} H_{j}+\gamma_{1} X_{i j}+\theta_{1} T_{j}+\delta_{1} D_{j}+\lambda_{1} A_{i j}+\varepsilon_{1 i j}
$$

where $i$ and $j$ indexes child and family. $Y_{i j}$ is some outcome (i.e. school enrollment) and $H_{j}$ is the treatment variable as defined above. $T_{j}, D_{j}, A_{i j}$ are a set of dummy variables

\footnotetext{
${ }^{14}$ The $\mathrm{p}$ value from an F-test of joint significance of all pre-intervention characteristics on the time to convert is 0.55 , while the one on the time of the survey is 0.05 .
} 
Table 3. Exogeneity of time variables

\begin{tabular}{|c|c|c|}
\hline Variable & $\begin{array}{l}\text { Time to convert } \\
\text { (1) }\end{array}$ & $\begin{array}{c}\text { Time of the survey } \\
\text { (2) }\end{array}$ \\
\hline Treatment & $\begin{array}{c}-27.873 * * * \\
(7.465)\end{array}$ & $\begin{array}{c}42.041 * * * \\
(4.400)\end{array}$ \\
\hline SELBEN & $\begin{array}{c}0.176 \\
(0.468)\end{array}$ & $\begin{array}{l}-0.197 \\
(0.265)\end{array}$ \\
\hline Household size & $\begin{array}{l}3.237^{*} \\
(1.753)\end{array}$ & $\begin{array}{l}1.944^{*} \\
(1.140)\end{array}$ \\
\hline Number of adults & $\begin{array}{c}5.559 \\
(3.735)\end{array}$ & $\begin{array}{c}3.192 \\
(2.350)\end{array}$ \\
\hline Number of children & $\begin{array}{c}2.746 \\
(2.199)\end{array}$ & $\begin{array}{c}1.704 \\
(1.214)\end{array}$ \\
\hline Schooling mother & $\begin{array}{l}-0.522 \\
(0.812)\end{array}$ & $\begin{array}{c}0.483 \\
(0.406)\end{array}$ \\
\hline Schooling head & $\begin{array}{l}-0.035 \\
(0.799)\end{array}$ & $\begin{array}{l}-0.298 \\
(0.412)\end{array}$ \\
\hline Age mother & $\begin{array}{c}0.218 \\
(0.279)\end{array}$ & $\begin{array}{l}-0.123 \\
(0.161)\end{array}$ \\
\hline If $\mathrm{HH}$ head is indigeneous & $\begin{array}{l}-21.671 \\
(24.165)\end{array}$ & $\begin{array}{c}52.621 * * * \\
(19.683)\end{array}$ \\
\hline If $\mathrm{HH}$ head is employed & $\begin{array}{c}3.561 \\
(10.034)\end{array}$ & $\begin{array}{c}1.11 \\
(5.003)\end{array}$ \\
\hline If $\mathrm{HH}$ head earns income & $\begin{array}{l}-29.123 \\
(21.231)\end{array}$ & $\begin{array}{c}-5.298 \\
(10.226)\end{array}$ \\
\hline If $\mathrm{HH}$ head is disabled & $\begin{array}{c}5.851 \\
(25.953)\end{array}$ & $\begin{array}{c}8.052 \\
(22.047)\end{array}$ \\
\hline$N($ Households $)$ & 2342 & 2342 \\
\hline
\end{tabular}

Note: Each estimate results from a separate regression of the time variable on different pre-intervention characteristics. Robust standard errors clustered at the level of the household are presented in parentheses. $* / * * / * * *$ denotes significance at $10 / 5 / 1 \%$ confidence level. 
Figure 3. First approach for identification

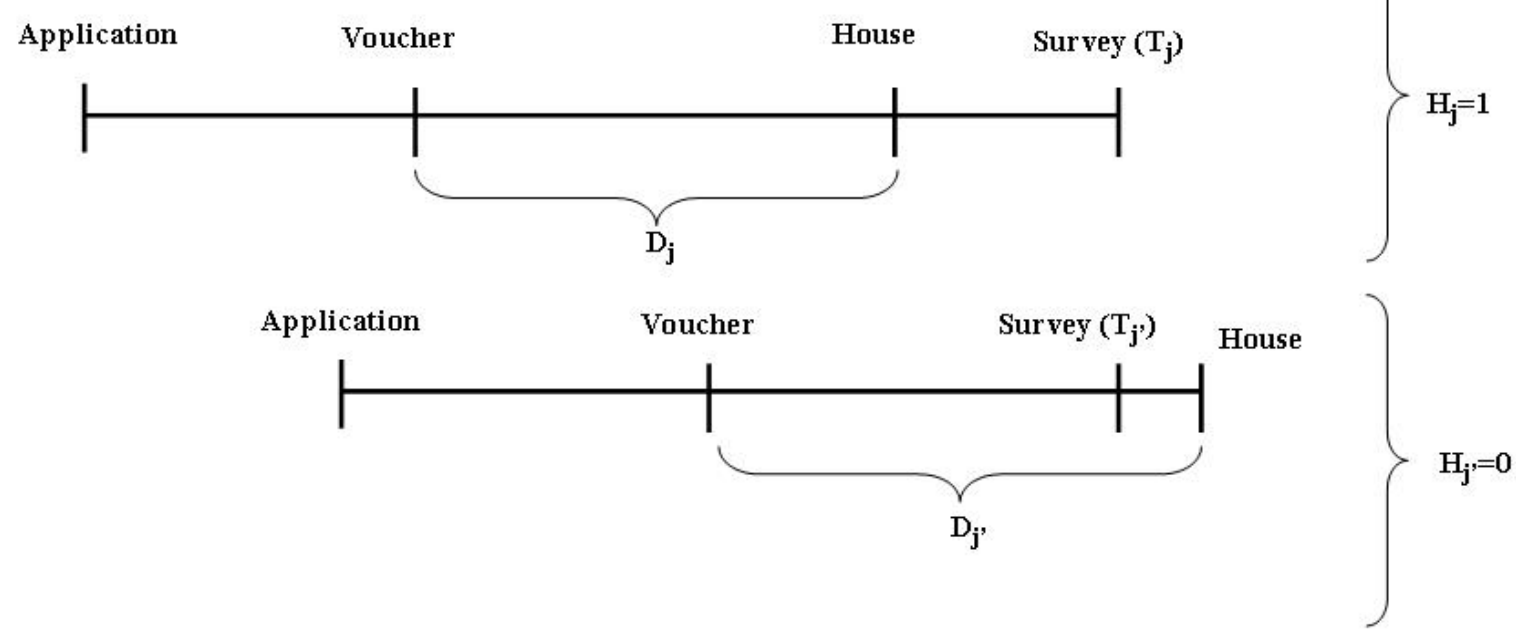

(fixed effects) for each possible category of time of survey, time for conversion and age respectively. $X_{i j}$ is a set of pre-treatment characteristics of the child and families used as control variables. The impact of the intervention is captured by the coefficient $\beta_{1}$.

Equation (1) can be extended to fully exploit the panel nature of the SELBEN survey and estimate a difference-in-differences estimator. To identify an effect, this estimator combines differences in outcomes between treated and control groups, with differences over time within the groups. The resulting equation is:

$$
Y_{i j t}=\alpha_{2}+\beta_{2} H_{j}+\pi_{2} d_{t}+\omega_{2} H_{j} \cdot d_{t}+\gamma_{2} X_{i j}+\theta_{2} T_{j}+\delta_{2} D_{j}+\lambda_{2} A_{i j}+\varepsilon_{2 i j t}
$$

where $d_{t}$ is an indicator for pre and post intervention, $H_{j} \cdot d_{t}$ is an interaction term and $\omega_{2}$ measures the effect of the program. Although the same identifying assumption as for the single difference estimator of equation (1) applies, the double difference estimator controls for a new set of unobservable characteristics which do not vary with time within the groups and might jointly affect the date of application and the outcomes.

The second approach for identification uses the information of the composition of the families in the sample to exploit the variation in outcomes across siblings within families that arises from the fact that siblings get the program at different ages. In this sense, we can compare a child that has been treated by the intervention using as a comparison group an older sibling within the family that, at the same age as the treated child, did not benefit from the intervention. By comparing their outcomes at that specific age, we can control for unobserved family characteristics that are common for children within a family such as the urgency in the need for a house, their access to information about social programs or the ability to convert the bonus into a house. 
The identifying assumption for this approach is that differences on unobserved child specific characteristics are not jointly correlated with the outcomes and the probability of being treated at a certain age. However, in a recent paper, De Haan et al. (2012) show compelling evidence of a positive effect of birth order on educational outcomes. If that is the case, we could expect the within family estimates of having a house to be biased upwards since younger children would experience better outcomes even in the absence of the program. In order to correct for this bias I use the variation between older and younger siblings, at a specific age, in families that have not been exposed to the program (untreated families). The latter assumes that the difference in outcomes between younger and older siblings in untreated families measures the no-intervention difference between younger and older siblings in treated families.

Formally, the second approach boils down to a difference-in-differences estimation that uses the following regression:

$$
Y_{i j a}=\alpha_{3}+\phi_{j}+\beta_{3} E_{i j e}+\omega_{3} E_{i j e} \cdot H_{j}+\gamma_{3} X_{i j}+\varepsilon_{i j a}
$$

where $Y_{i j a}$ is an outcome of child $i$ in family $j$ at a specific age $a$, for example 14 years old. $H_{j}$ is a binary indicator where $H_{j}=1$ if a child belongs to a treated family and 0 otherwise. $E_{i j e}$ is a dummy variable that defines within a family the younger sibling. It equals 1 either if a child $i$ in a treated family converted the voucher at moment $e$, where $e \leq a$, or if a child $i$ in an untreated family has an age at the moment of the survey $\left(a^{s}\right)$ that is equal or less than $a$. Likewise, the dummy variable is 0 if a child in a treated family was exposed to the new house in a later age than $a$ (older sibling) or if a child in an untreated family is older than $a$ at the moment of the survey. $\phi_{j}$ is a family fixed effect, $E_{i j e} \cdot H_{j}$ is the interaction term and $\omega_{3}$ measures the effect of the being exposed to the program relative to not being exposed controlled by the differences between younger and older siblings in the untreated families. A diagram of this approach is shown in Figure 4. While the SELBEN-panel allows me to create enrollment of a child at a specific age, as described in Section 4, this process can not be replicated for other outcomes of interest in this analysis such as child labor. ${ }^{15}$

\footnotetext{
${ }^{15}$ Following Fertig and Reingold (2007) an instrumental variable approach was also tried. In order to instrument the condition of receiving a voucher and being able to convert it into a house, two variables were used: gender composition of the households and the geographical (canton) variation on the supply of new houses. Although there is general acknowledgment of the limitations on the validity of these two instruments as they might also be correlated with outcomes (Butcher and Case, 1994; Newman and Harkness, 2002) the instruments proved to be not relevant given the partial F statistic of the first stage regressions.
} 
Figure 4. Second approach for identification
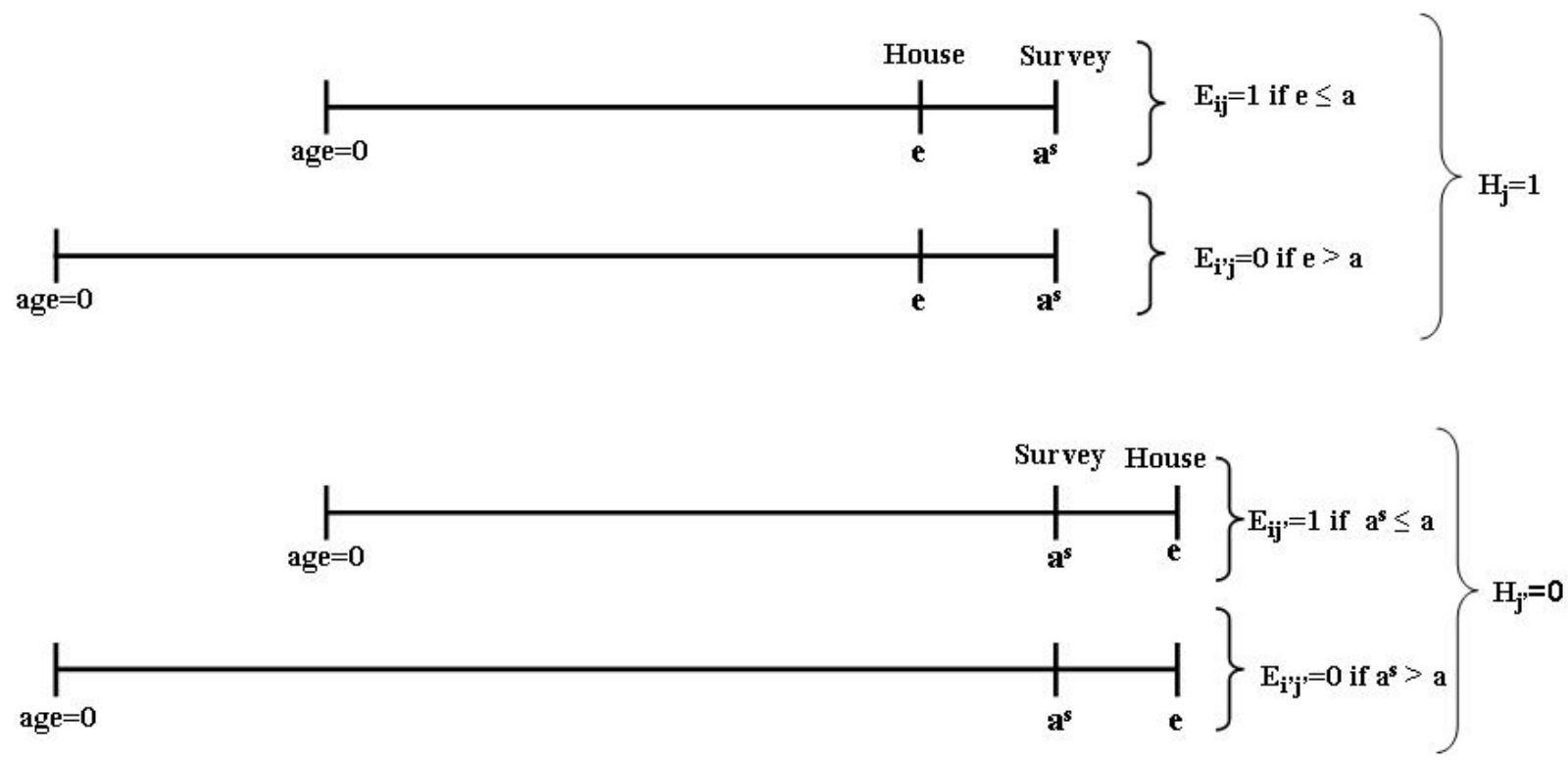

\section{Results}

\subsection{Children outcomes}

Table 4 reports the estimates of the impact of the housing assistance program on school enrollment and child labor. Note that the estimates in this table are based on the specifications in equations (1) and (2) which use the first approach. The first two columns present the results for the whole sample of children with age ranged 8 to 18 years old in the second SELBEN survey. The other columns present the results divided by age intervals: children younger than 15 years old, and children older than 15 years old. The age intervals reflect the transition of children in Ecuador from compulsory school to post-compulsory school where the likelihood of dropping out of school is largest.

Results are given for different specifications corresponding to varying sets of controls. The first specification uses no control variables and, therefore, makes no additional attempt to account for potential bias other than comparing treated and control children within a sample of approved applicant families. The second specification includes an extended set of pre-treatment control variables such as gender of the child, parental education (separately for each parent), age of the mother, a measure of household size and household composition, an index of socioeconomic status and dummy variables for whether the head of the household was indigenous, disabled, employed, or received an income. The third and fourth specifications add dummy variables for the time of the SELBEN survey and the time elapsed to convert the voucher, respectively. ${ }^{16}$ The fifth

\footnotetext{
${ }^{16}$ This is implemented by dividing each of the two time variables in deciles and creating a set of dummy
} 
specification controls for both sets of dummies at the same time while the sixth specification also includes a dummy for age of the children. In this way, the last specification compares treated and untreated children of similar age in families that were surveyed by SELBEN in the same period of time and that spend the same amount of time to convert the voucher into a house.

Focusing on the regressions that use the whole sample of children, the sign of the estimated effect of the housing program in all the specifications points to an improvement in school enrollment and a reduction in child labor. More importantly, while the size of the effect changes only slightly with the inclusion of different sets of controls, their statistical significance varies. In the specification that includes all fixed effects (row 6) none of the effects is statistically significant.

When the treatment effects are broken down by age intervals (compulsory and postcompulsory education) the results show a clear pattern in all specifications. While having an own and adequate house does not have an effect on school enrollment and child labor for children in the compulsory school age, it has a positive and significant effect on improving the enrollment of children in post-compulsory school and reducing the likelihood of working for children between 15 and 18 years old. As for the whole sample, the effects of the program change only slightly with the inclusion of control variables and the inclusion of different combinations of dummies for the time variables.

The last row of table 4 presents the difference-in-differences estimates which exploits the pre-treatment information and controls for a new set of unobservable individual characteristics which do not vary with time. Compared to the results of the other specifications, these estimates show little difference in magnitude and point in the same direction. In the transition age between compulsory and post-compulsory school, being treated by the program has a positive and significant effect on improving child enrollment by 4.6 percentage points, and a significant effect on reducing child labor by 4.4 percentage points with respect to the untreated children. Relative to the base school enrollment and child labor rates, the size of these effects is substantial. They translate into a 19 percent reduction in the drop out rate from the non compulsory track of the educational system and into a 21 percent decline in the fraction of working children at this age range.

Results of the impact of the program on poverty reduction measured by the welfare index are presented in Table 5. While the first column presents the estimates using the welfare index that includes dwelling characteristics and access to services, the second column presents estimates that excludes these characteristics which are considered to be a mechanic output of the intervention. Focusing on the most extended specification including control variables and fixed effects in row (6), the estimate shows that being exposed variables for each decile category. 
Table 4. Results for children outcomes. First approach

\begin{tabular}{|c|c|c|c|c|c|c|}
\hline \multirow[b]{2}{*}{ Specification } & \multicolumn{2}{|c|}{8 to 18} & \multicolumn{2}{|c|}{15 to 18} & \multicolumn{2}{|c|}{8 to 14} \\
\hline & $\begin{array}{c}\text { Enrollment } \\
\text { (1) }\end{array}$ & $\begin{array}{c}\text { Child labor } \\
\text { (2) }\end{array}$ & $\begin{array}{c}\text { Enrollment } \\
\text { (3) }\end{array}$ & $\begin{array}{c}\text { Child labor } \\
\text { (4) }\end{array}$ & $\begin{array}{c}\text { Enrollment } \\
\text { (5) }\end{array}$ & $\begin{array}{c}\text { Child labor } \\
\text { (6) }\end{array}$ \\
\hline \multirow[t]{2}{*}{ (1) No Controls } & $0.025^{*}$ & -0.016 & $0.045^{* *}$ & $-0.038^{*}$ & 0.012 & 0.000 \\
\hline & $(0.014)$ & $(0.013)$ & $(0.022)$ & $(0.021)$ & $(0.012)$ & $(0.009)$ \\
\hline \multirow[t]{2}{*}{ (2) $X$} & $0.025^{*}$ & $-0.020^{*}$ & $0.040^{*}$ & $-0.036^{*}$ & 0.005 & 0.001 \\
\hline & $(0.013)$ & $(0.011)$ & $(0.021)$ & $(0.019)$ & $(0.012)$ & (0.009) \\
\hline \multirow[t]{2}{*}{ (3) $X_{j}, T_{j}$} & $0.024 *$ & -0.018 & $0.037 *$ & $-0.032 *$ & 0.007 & 0.000 \\
\hline & $(0.014)$ & $(0.012)$ & $(0.023)$ & $(0.020)$ & $(0.012)$ & $(0.009)$ \\
\hline \multirow[t]{2}{*}{ (4) $X_{j}, D_{j}$} & $0.028^{* *}$ & $-0.024 *$ & $0.045^{* *}$ & $-0.042 * *$ & 0.000 & 0.004 \\
\hline & $(0.014)$ & $(0.012)$ & $(0.021)$ & $(0.020)$ & $(0.013)$ & $(0.010)$ \\
\hline \multirow{2}{*}{ (5) $X_{j}, T_{j}, D_{j}$} & $0.025^{*}$ & $-0.021^{*}$ & $0.041^{*}$ & $-0.038^{*}$ & 0.001 & 0.004 \\
\hline & $(0.014)$ & $(0.012)$ & $(0.022)$ & $(0.021)$ & $(0.014)$ & $(0.010)$ \\
\hline \multirow[t]{2}{*}{ (6) $X_{j}, T_{j}, D_{j}, A$} & 0.020 & -0.017 & $0.038 *$ & $-0.036^{*}$ & 0.001 & 0.003 \\
\hline & $(0.014)$ & $(0.012)$ & $(0.022)$ & $(0.021)$ & $(0.014)$ & $(0.010)$ \\
\hline \multirow[t]{2}{*}{ (7) Dif in Dif } & $0.026 *$ & $-0.021 *$ & $0.046 *$ & $-0.044 * *$ & 0.003 & 0.003 \\
\hline & $(0.014)$ & $(0.013)$ & $(0.023)$ & $(0.022)$ & $(0.014)$ & $(0.010)$ \\
\hline Mean for controls & 0.850 & 0.114 & 0.760 & 0.203 & 0.939 & 0.025 \\
\hline SD for controls & 0.357 & 0.317 & 0.427 & 0.402 & 0.239 & 0.155 \\
\hline$N$ & 3304 & 3304 & 1671 & 1671 & 1633 & 1633 \\
\hline
\end{tabular}

Note: Each estimate results from a separate regression using different specifications of equations 1 and 2. Robust standard errors clustered at the level of the household are presented in parentheses. $* / * * / * * *$ denotes significance at $10 / 5 / 1 \%$ confidence level. The set of variables $X$ includes all the control variables in Table 2. $T_{j}, D_{j}$ and $A_{j}$ are a set of dummy variables for each possible category of time of survey, time for conversion and age respectively. 
Table 5. Results on poverty reduction. First approach

\begin{tabular}{lcc}
\hline Specification & $\begin{array}{c}\text { Welfare index } \\
\text { with infrastructure }\end{array}$ & $\begin{array}{c}\text { Welfare index } \\
\text { without infrastructure }\end{array}$ \\
& $(1)$ & $(2)$ \\
\hline (1) No Controls & $1.610^{* * *}$ & $0.961^{* *}$ \\
& $(0.418)$ & $(0.375)$ \\
(2) $X$ & $1.168^{* * *}$ & 0.545 \\
& $(0.375)$ & $(0.340)$ \\
(3) $X_{j}, T_{j}$ & $1.388^{* * *}$ & $0.749^{* *}$ \\
& $(0.382)$ & $(0.342)$ \\
(4) $X_{j}, D_{j}$ & $1.025^{* * *}$ & 0.418 \\
& $(0.395)$ & $(0.353)$ \\
(5) $X_{j}, T_{j}, D_{j}$ & $1.276^{* * *}$ & $0.666^{*}$ \\
& $(0.405)$ & $(0.360)$ \\
(6) Dif in dif & $1.492^{* * *}$ & $1.019^{* * *}$ \\
& $(0.402)$ & $(0.367)$ \\
Mean controls & 5.187 & 4.204 \\
SD controls & 8.898 & 7.979 \\
$N$ (Households) & 2342 & 2342
\end{tabular}

Note: Each estimate results from a separate regression using different specifications of equations 1 and 2. Robust standard errors clustered at the level of the household are presented in parentheses. $* * * * * * * *$ denotes significance at $10 / 5 / 1 \%$ confidence level. The set of variables $X$ includes all the control variables in Table 2. $T_{j}, D_{j}$ and $A_{j}$ are a set of dummy variables for each possible category of time of survey, time for conversion and age respectively.

to the program and succeeding to have an own and adequate house increases the welfare of the family (decrease its poverty) by 1.5 points of the index or 16 percent of a standard deviation of the index for the untreated families. The latter is not sensitive to the exclusion of all the variables that are related to the dwelling infrastructure and access to services. According to these estimates, treated families are less poor as they improve their level of welfare by 1 point of the index which translates to an increase of their welfare of 12 percent of a standard deviation.

Table 6 presents the within family estimates of the effect of the housing program based on equation 3 which controls for unobserved family characteristics that are common for a child within a family and can not be taken into account in the previous approach. Specifically, this approach compares the enrollment rate at a specific age between siblings of different age at survey and between families with and without a child that was exposed to the program. To contrast the results of this approach to the results obtained with the first approach, Table 6 reports estimates in the neighborhood of the transition age from compulsory to post-compulsory school (14 to 15 years old).

Columns (1), (2) and (3) present the estimates of the effect of the program on enroll- 
Table 6. Results on child outcomes. Second approach.

\begin{tabular}{lcccccc}
\hline \multirow{2}{*}{ Specification } & $a=12$ & $a=13$ & $a=14$ & $a=15$ & $a=16$ & $a=17$ \\
& $(1)$ & $(2)$ & $(3)$ & $(4)$ & $(5)$ & $(6)$ \\
\hline$E_{i j e} . H_{j}$ at age $\leq a$ & -0.014 & 0.028 & 0.008 & $0.094^{* *}$ & 0.006 & -0.077 \\
& $(0.034)$ & $(0.028)$ & $(0.042)$ & $(0.054)$ & $(0.061)$ & $(0.077)$ \\
$E_{i j e} . H_{j}$ at age $\leq a, X$ & -0.014 & 0.030 & 0.001 & $0.094^{* *}$ & 0.004 & -0.077 \\
& $(0.034)$ & $(0.028)$ & $(0.042)$ & $(0.054)$ & $(0.060)$ & $(0.080)$ \\
Mean controls & 0.914 & 0.889 & 0.859 & 0.789 & 0.740 & 0.718 \\
$S D$ controls & 0.279 & 0.313 & 0.347 & 0.384 & 0.407 & 0.444 \\
$N$ & 5243 & 4587 & 3861 & 3202 & 2612 & 1993 \\
\hline
\end{tabular}

Note: Each estimate results from a separate regression using the within family approach of equation 3. Robust standard errors clustered at the level of the household are presented in parentheses. */****** denotes significance at $10 / 5 / 1 \%$ confidence level.

ment in compulsory school, ages 12,13 and 14 respectively and point out that children exposed to the program at these ages are not more likely to be enrolled than their older siblings at the same age. Column (4) estimates the effect of the program at the transition age to non compulsory school and finds a substantial positive and significant effect. Being treated at age 15 or before increases school enrollment by 9 percentage points compared to the enrollment faced by their older untreated siblings at the same age. Compared to the enrollment rate at age 15 , it represents a $44 \%$ reduction in the likelihood of dropping out from the post-compulsory track of the educational system at this specific age. These results confirm the direction and the significance of the estimates obtained from the first approach. Columns (5) and (6) reports the estimates at age 16 and 17 which are smaller in size and less precise than the previous ones. I interpret these estimates as an indication that the timing of the intervention is important to have an effect on school enrollment at the transition ages. Considering the sharp dropout of students between 14 and 15 years old and the inherent difficulty of recruiting students once they have left the educational system, the effect of having an own and adequate house on children exposed at later ages (i.e. 16 or 17 years old) is marginal or nonexistent.

\subsection{Interpreting the results}

The estimates mentioned above suggest that there is a causal effect of the housing program on post compulsory enrollment and child labor. One concern in interpreting these estimates is that there may be alternative explanations that could drive the direction of the results. This subsection aims to test for such alternative explanations in different ways. First, I consider if there might be an independent effect of the expectancy of moving on the control group that might bias upwards the effect found for the treated group. Second, 
I investigate if there might be a separate effect of moving (disruption effect) that may change the behavior of the treated children in the short run and attenuate the estimated effect.

\section{Anticipation effects of moving on the control group}

In order to interpret the estimates as a causal, an implicit assumption is that there is no anticipation effects of moving that might independently affect the behavior of children in the control group. Recall that the control group consists of accepted applicant families that are in the process of converting the voucher to a house. In this case, it is possible that close to the moving day, families in this group may delay the decision of school enrollment until the moment they arrive to their new location. Similarly, in expectancy of moving, children might feel less attached to their current schools and might end dropping out from them and devoting time to the labor market. If that is the case, we could expect our estimates to be biased upwards as children in the control group would experience an unintended negative effect of the program before they get a new house.

To investigate the presence of anticipation effects, equation 1 is estimated over the sample of untreated children where $H_{j}$ is redefined to be equal to one for children close to the moving day and 0 otherwise. I define closeness as being less than 180 days away from moving to a new house. ${ }^{17}$ A significant estimate would reveal if there are differences between the two groups of children that might be interpreted as an indication of a behavioral response of the children which are closer to the moving day. The results of this analysis are presented in the upper panel of Table 7 and show no indication of such differences indicating that the main results are not driven by this alternative channel.

\section{Disruption effects of moving on the treatment group}

While the outcome of a housing assistance program is expected to be beneficial to the family and its members, it also involves a process a reallocation to a new environment which normally entails a new school with a likely unfamiliar curriculum and a different set of peers. These factors have the potential to be disruptive to a child's involvement and attachment to the educational system. Several studies have documented the negative association between children mobility and student achievement although most coincide that the disruption is more likely to affect the children in the short run (immediately after moving) and be fully reversed in the long run (Kerbow, 1996; Kain and O'Brien, 1998; Hanushek et al., 2004).

As the outcomes for treated children were collected after a median of 323 days of exposure, one possible interpretation of the estimates above is that they are confounded

\footnotetext{
${ }^{17}$ Almost $50 \%$ of the households in the control group are less than 180 days away from the moving day. The results shown below are not sensitive to the selection of other cut off points.
} 
Table 7. Specification checks

\begin{tabular}{lccc}
\hline & 8 to 18 & 15 to 18 & 8 to 14 \\
\hline A. Placebo: Expectation to move & & & \\
Enrollment & -0.002 & 0.014 & -0.019 \\
& $(0.021)$ & $(0.033)$ & $(0.021)$ \\
Child Labor & 0.013 & 0.016 & 0.005 \\
& $(0.016)$ & $(0.028)$ & $(0.013)$ \\
$N$ & 2192 & 1091 & 1101 \\
& & & \\
B. Placebo: Disruption of moving & & & \\
Enrollment & 0.009 & 0.017 & 0.005 \\
& $(0.013)$ & $(0.022)$ & $(0.012)$ \\
Child Labor & -0.006 & -0.016 & 0.001 \\
& $(0.012)$ & $(0.020)$ & $(0.009)$ \\
$N$ & 3420 & 1727 & 1693 \\
\hline
\end{tabular}

Note: Each estimate results from a separate regression using equation 1. Robust standard errors clustered at the level of the household are presented in parentheses. $* / * * * * *$ denotes significance at $10 / 5 / 1 \%$ confidence level.

with a potential negative and independent effect caused by the reallocation process. If this is the case, an estimation of the effect of the program would be attenuated towards not finding an impact. To test for this I make use of the data of children in families that were able to convert the voucher and that have been exposed to the new house for less than 180 days. I define these individuals as a placebo treatment group in equation 1 which is compared to the complete group of untreated families. A significant estimate in this specification would give an indication of the presence of a disruption effect which is independent from the intended impact of the program. The second panel of Table 7 reports the results of this specification and shows that there are no statistical differences between the placebo and the untreated children confirming that there is no sign of a disruption effect on children after moving.

\subsection{Potential mechanisms}

Next I look at the impact of the program on variables that may mediate the effect of having an own and adequate house on child outcomes and poverty. Specifically I test if housing assistance provides a better physical environment to families than the one experienced in the absence of the program and if the program induces families to move to better, less poor neighborhoods.

Results for outcomes that represent the quality of the house's physical environment are presented from column 1 to 4 in Table 8 using the equations 1 and 2. These outcomes include access to sanitation, quality of the floor (cement or table instead of dirt) and the 
availability of a shower in the house which is a proxy for family's access to a source of safe water. As in Table 4, the results are presented for different specifications which include different sets of control variables and dummy variables. The results reveal a clear pattern. According to the most extensive specification in row (6) the difference-in-differences estimates report positive effects of the program on all the housing environment variables. Being treated with the program and having succeeded to get a new house improve the availability of a shower in the house by 20 percentage points (relative to a base of $47 \%$ ), increases the access to sanitation by 7.5 percentage points (relative to a base of $71 \%$ ) and improves the probability of having a cement or table floor by 8 percentage points (relative to a base of $88 \%$ ). In the same way, there is a substantial effect in decreasing overcrowding by 19 percentage points (relative to a base of $46 \%$ ).

Table 8. Results on housing environment and access to poorer neighborhoods

\begin{tabular}{|c|c|c|c|c|c|c|}
\hline Specification & Shower & Sanitation & Floor & Overcrowding & $\begin{array}{c}\text { Poor } \\
\text { Neighborhood } \\
(5)\end{array}$ & $\begin{array}{c}\text { Extreme Poor } \\
\text { Neighborhood } \\
\text { (6) }\end{array}$ \\
\hline (1) No Controls & $\begin{array}{c}0.206 * * * \\
(0.024)\end{array}$ & $\begin{array}{c}0.124 * * * \\
(0.021)\end{array}$ & $\begin{array}{c}0.093 \text { *** } \\
(0.012)\end{array}$ & $\begin{array}{c}-0.221 * * * \\
(0.022)\end{array}$ & $\begin{array}{c}0.008 \\
(0.011)\end{array}$ & $\begin{array}{c}0.001 \\
(0.011)\end{array}$ \\
\hline (2) $X$ & $\begin{array}{c}0.197 * * * \\
(0.024)\end{array}$ & $\begin{array}{c}0.114 * * * \\
(0.019)\end{array}$ & $\begin{array}{c}0.091 * * * \\
(0.012)\end{array}$ & $\begin{array}{c}-0.218 * * * \\
(0.022)\end{array}$ & $\begin{array}{c}0.013 \\
(0.011)\end{array}$ & $\begin{array}{c}0.005 \\
(0.011)\end{array}$ \\
\hline (3) $X_{j}, T_{j}$ & $\begin{array}{c}0.197 * * * \\
(0.024)\end{array}$ & $\begin{array}{c}0.113 * * * \\
(0.019)\end{array}$ & $\begin{array}{c}0.095 * * * \\
(0.012)\end{array}$ & $\begin{array}{c}-0.216^{* * *} \\
(0.022)\end{array}$ & $\begin{array}{c}0.012 \\
(0.011)\end{array}$ & $\begin{array}{c}0.01 \\
(0.011)\end{array}$ \\
\hline (4) $X_{j}, D_{j}$ & $\begin{array}{c}0.214 * * * \\
(0.024)\end{array}$ & $\begin{array}{c}0.111 * * * \\
(0.020)\end{array}$ & $\begin{array}{c}0.088 * * * \\
(0.012)\end{array}$ & $\begin{array}{c}-0.215^{* * *} \\
(0.023)\end{array}$ & $\begin{array}{c}0.009 \\
(0.011)\end{array}$ & $\begin{array}{c}0.003 \\
(0.011)\end{array}$ \\
\hline (5) $X_{j}, T_{j}, D_{j}$ & $\begin{array}{c}0.217 * * * \\
(0.025)\end{array}$ & $\begin{array}{c}0.110 * * * \\
(0.020)\end{array}$ & $\begin{array}{c}0.093 * * * \\
(0.012)\end{array}$ & $\begin{array}{c}-0.210 * * * \\
(0.024)\end{array}$ & $\begin{array}{c}0.008 \\
(0.011)\end{array}$ & $\begin{array}{c}0.006 \\
(0.011)\end{array}$ \\
\hline (6) DD & $\begin{array}{c}0.210 * * * \\
(0.029)\end{array}$ & $\begin{array}{c}0.073 * * \\
(0.032)\end{array}$ & $\begin{array}{c}0.083 * * * \\
(0.018)\end{array}$ & $\begin{array}{c}-0.197 * * * \\
(0.030)\end{array}$ & $\begin{array}{c}-0.01 \\
(0.010)\end{array}$ & $\begin{array}{l}-0.002 \\
(0.009)\end{array}$ \\
\hline Mean controls & 0.471 & 0.716 & 0.882 & 0.469 & 0.688 & 0.369 \\
\hline SD controls & 0.499 & 0.451 & 0.322 & 0.499 & 0.187 & 0.369 \\
\hline$N($ Households $)$ & 2342 & 2342 & 2342 & 2342 & 2342 & 2342 \\
\hline
\end{tabular}

Note: Each estimate results from a separate regression using the fixed effect approach of equations 1 and 2. Robust standard errors clustered at the level of the household are presented in parentheses. $* / * * / * * *$ denotes significance at $10 / 5 / 1 \%$ confidence level. The set of variables $X$ includes all the control variables in Table 2.

Columns 5 and 6 of Table 8 present the estimated effect of the program on inducing treated families to move and live in better neighborhoods. I define a neighborhood as a census tract based on Ecuador's Census of 2001. The quality of a neighborhood is identified by the percentage of households within a tract with a family consumption below the poverty line. For the estimation I match the data used in the analysis with the Ecuadorian Poverty Map (MCDS-BID, 2007) at the level of census tract. A better neighborhood is 
characterized as a census tract with a smaller portion of low income households (poor households) living inside its boundaries. The results of the most extensive specification in row (6) show that although treated families have succeeded to get a new house, they live in neighborhoods that are on average equally poor as the ones in which they used to live before the program if compared to the untreated families.

Although I can not confirm or rule out the presence of other mediating factors that could explain the results on children outcomes such as more stability or better parenting skills, it seems clear that the intervention has a positive effect on providing a better physical environment for families than the one experienced in the absence of the program and a neutral effect on inducing families to move to better neighborhoods where children might have been exposed to more advantaged peers or better role models.

\section{Conclusions}

Despite the fact that housing is high on the policy agenda in developed and developing countries, the effects of housing assistance programs on the well-being of families and children have been seriously understudied. This paper contributes to fill this gap by evaluating the effect of a greatly promoted $\mathrm{ABC}$ housing assistance program in Ecuador on children's human capital measured by school enrollment and the likelihood of child labor. This is especially important as it has the potential to achieve long term poverty reduction by improving children prospects to live a productive life in adulthood.

The ABC program grants a single voucher to poor families that can be used to support part of a new house investment which is complemented by family's savings and a mortgage loan. The results show that being treated by the program and succeeding in converting the voucher into a house has a positive effect on enrollment in post-compulsory education. Moreover, this paper gives evidence that the program also has a significantly negative effects on child labor. The size of the estimates after almost one year of exposure to the new house are particularly large, that is, they correspond with a 19 percent decrease in the dropout rate from the post-compulsory track of the educational system and with a 21 percent decline in the fraction of working children in this age range. Considering that housing policies are not primarily aimed at improving school enrollment and child labor but they are considered to be social externalities that represents no further cost, the additional return estimated by this analysis is quite high.

There are only two other impact evaluation studies in Ecuador of programs that, unlike a housing intervention, have as a primary objective to increase either school enrollment or attendance. In the first study Oosterbeek et al. (2008) evaluate a cash transfer program consisting of US\$15 per month targeted to the 40 percent poorest families and find that 
while the intervention decreases the school dropout rate by 40 percent for children in the first quintile of the SELBEN index, there is no effect for children in the second quintile. In the second study, Hidalgo et al. (2010) analyze the effect of a program that provides free uniforms to children in the first 6 years of school (former primary education). This study finds that the program has a negative effect equivalent to a $50 \%$ increase in the absenteeism of treated children.

The results in this paper contrast with the ones obtained by Marcano (2010) for the same program in Ecuador. By applying matching techniques, he finds no effects of the program using an extremely small sample of voucher recipients that can not be identified to have converted it into a house. This study overcomes most of its limitations as it uses a much larger sample of accepted applicants, it identifies families that have been actually exposed to a house and uses more credible sources of variation to identify a causal effect.

With respect to poverty reduction, this paper shows evidence that being exposed to the program and succeeding to have an own and adequate house increases the estimated welfare of the family and, therefore, reduces its likelihood to be considered poor. The latter indicates the relevance of including this type of housing policies in a poverty reduction strategy.

Although the data available for this analysis do not allow to disentangle all the underlying mechanisms that may explain these effects, this paper has tested if housing assistance provides a better physical environment to families and if the program induce families to move to better, less poor neighborhoods. On one hand, if housing assistance provides a better physical environment to families than the one experienced in the absence of the program and thereby leads to an improvement in the health status of the children exposed to the program, it might be considered a mechanism that can partially explain the results on children outcomes. On the other hand, if the program gives incentives to families to move to better neighborhoods, children outcomes might also benefit through the exposure to more advantaged peers, better role models or greater access to better social networks and local public goods.

The estimations of the effects on physical environment show that the program is highly effective to improve families' access to sanitation, safe water and better quality materials for the house. It also reduces the probability to live in an overcrowded condition. The estimations also shows that despite the fact that treated families succeed to get a new house, they do not move to better neighborhoods compared to the ones where the untreated families live. However, more research is necessary to get a better understanding on the importance of other mediating mechanisms such as income effects, better parenting and stability.

The evidence of this paper is especially relevant for policy makers in developing coun- 
tries that have as goals the design of policies aimed at preventing the massive dropout of students from poor families in the post-compulsory track while also preventing child labor. The results highlight the fact that social benefits of housing should not be underestimated and should be taken into account as a key element in a strategy to overcome the vicious circle of poverty. Future research should be targeted to test the effect of housing assistance programs in rural areas where the fall in the enrollment rate during the transition to post-compulsory school is much larger. It is also important to analyze the impact of programs aimed at improving the current quality of the house instead of assisting families to get a new house.

\section{References}

Aaronson, D. (2000). A note on the benefits of homeownership. Journal of Urban Economics, 47:356-369.

Almond, D. and Currie, J. (2010). Human capital development before age five. Technical report, National Bureau of Economic Research.

Arnott, R. (2008). Housing Policy in Developing Countries: The Importance of the Informal Economy. The World Bank.

Astone, N. and McLanahan, S. (1994). Family structure, residential mobility, and school dropout: A research note. Demography, 34:575-584.

Becker, G. (1964). Human Capital: A Theoretical and Empirical Analysis, with special reference to Education. Chicago: University of Chicago Press.

Brooks-Gunn, J., Duncan, G. J., and Lawrence, A. (1997). Neighborhood Poverty: Context and consequences for kids. New York: Russell Sage Foundation, 1997.

Buckley, R. and Kalarickal, J. (2006). Thirty Years of World Bank Shelter Lending. World Bank.

Cattaneo, M., Galiani, S., Gertler, P., Martinez, S., and Titiunik, R. (2009). Housing, health and happiness. Amercian Economic Journal: Economic Policy, 1:75-105.

Coggon, D., Barker, D., Inskip, H., and Wield, G. (1993). Housing in early life and later mortality. Journal of Epidemiology and Community Health, 47:345-348.

Currie, J. and Yelowitz, A. (2000). Are public housing projects good for kids? Journal of Public Economics, 75:99-124. 
De Haan, M., Plug, E., and Rosero, J. (2012). Birth order and human capital development: Evidence from ecuador. Technical Report Dicussion Paper No. 6706, Institute for the Study of Labor (IZA).

Edmonds, E. (2005). Child labor and schooling responses to anticipated income in South Africa. Technical report, Department of Economics. Dartmouth College.

Ellen, I. and Turner, M. (1997). Does neighborhood matter? Assesing recent evidence. Housing Policy Debates, 8:833-866.

Elton, P. and Packer, J. (1996). A prospective randomized trial of the value of housing on the grounds of mental ill-health. Journal of Chronic Disease, 39:221-227.

Ferguson, B. and Navarrete, J. (2003). New approaches to progressive housing in Latin America: A key to Habitat programs and policy. Habitat International, 27:309-323.

Fertig, A. R. and Reingold, D. A. (2007). Public housing, health, and health behaviors: Is there a connection? Journal of Policy Analysis and Management, 26:831-859.

Frank, D. (2004). A market-based housing improvement system for low-income families. The housing incentive system (SIV) in Ecuador. Environment and Organization, 16(1):171-184.

Goux, D. and Maurin, E. (2005). The effect of overcrowded housing on children's performance at school. Journal of Public Economics, 89:797-819.

Green, R. and White, M. (1997). Measuring the benefits of homeownership: Effects on children. Journal of Urban Economics, 41:441-461.

Grossman, M. (1999). The human capital model of the demand for health. Technical report, National Bureau of Economic Research.

Hanushek, E., Kain, J., and Rivkin, S. (2004). Disruption versus tiebout improvement: the cost and benefits of switching schools. Journal of Public Economics, 88:1721-1746. Mimeo.

Hidalgo, D., Onofa, M., Oosterbeek, H., and Ponce, J. (2010). Can provision of free school uniforms harm attendance? Evidence from Ecuador. Discussion Papers 10103/3, Tinbergen Institute.

Hoxby, C. (2000). Would school choice change the teaching profession. Technical report, NBER. Working Paper No.7866.

IADB (2007). Statistics and indicators. 
Jacob, B. (2004). Public housing, housing vouchers and student achievement: Evidence from public housing demolitions in Chicago. American Economic Review, 94:233-258.

Jencks, C. and Mayer, S. (1990). The social consequences of Growing up in a Poor Neighborhood. Washington DC: National Academy Press.

Kain, J. and O'Brien, D. (1998). A longitudinal assessment of reading achievement: Evidence for the harvard/utd texas schools project. Technical report, University of Texas at Dallas.

Kerbow, D. (1996). Patterns of urban school mobility and local school reform. Journal of Education for Students Placed at Risk, 1:147-169.

Mann, S., Wadworth, M., and Colley, J. (1992). Accumulation of factors influencing respiratory illness in members of national birth cohort and their offspring. Journal of Epidemiology and Community Health, 46:286-292.

Marcano, L. (2010). La politica de vivienda social y su impacto en el bienestar: El caso de Ecuador. Technical report, Inter-American Development Bank (IADB).

Marcano, L. and Ruprah, I. J. (2008). An impact evaluation of Chile's Progressive Housing Program. Technical report, Inter-American Development Bank.

MCDS-BID (2007). Mapa de Pobreza y Desigualdad por Consumo en el Ecuador. Ministerio de Coordinacion de Desarrollo Social-Banco Interamericano de Desarrollo.

MIDUVI (1998-2010). Department of statistics of the ministry of housing. QuitoEcuador.

Nadin, F. and Almanza, M. (2010). Una evaluación de los programas públicos de vivienda ABC. Un estudio para Costa Rica. Technical report, Inter-American Development Bank.

Newman, S. J. and Harkness, J. M. (2002). The long-term effects of public housing on self-sufficiency. Journal of Policy Analysis and Management, 21:21-43.

Oosterbeek, H., Ponce, J., and Schady, N. (2008). The impact of cash transfers on school enrollment: Evidence from Ecuador. Policy Research Working Paper 4645, World Bank.

Pecha, C. (2010). Panama's housing program: An evaluation. Technical report, InterAmerican Development Bank. 
Pecha, C. (2011). Programa de vivienda de interés social de Colombia: Una evaluación. Technical report, Inter-American Development Bank.

Rosero, J. and Oosterbeek, H. (2011). Trade-offs between different early childhood interventions: Evidence from Ecuador. Discussion Papers 11-031/1, Tinbergen Institute. Mimeo.

Rossi, P. and Weber, W. (1996). The social benefits of homeownership: Empirical evidence from national surveys. Housing Policy Debates, 7:1-35.

Sanbonmatsu, L., Kling, J. R., Duncan, G. J., and Brooks-Gunn, J. (2006). Neighborhoods and academic achievement. Journal of Human Resoruces, 41:649-690.

Schultz, T. (2004). School subsidies for the poor: Evaluating the Mexican Progresa poverty program. Journal of Development Economics, 74:199-250.

Soto, H. D. (2000). The Mystery of Capitalism. New York, Basic Books. 